\title{
Brain volumetric correlates of inhibition and cognitive flexibility 16 years following childhood traumatic brain injury (TBI)
}

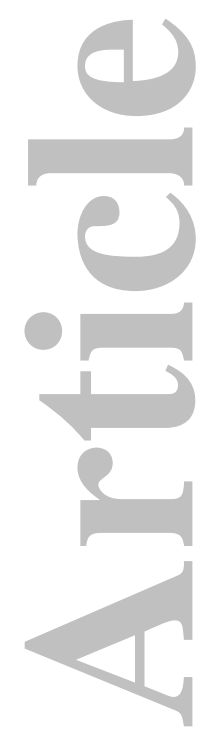

\author{
Kelleynne $\mathrm{Yu}^{1}$ \\ Marc L. Seal ${ }^{1,2}$ \\ Jonathan Reyes ${ }^{1}$ \\ Celia Godfrey ${ }^{1,2}$ \\ Vicki Anderson ${ }^{1,2,3,4}$ \\ Chris Adamson ${ }^{1}$ \\ Nicholas P. Ryan ${ }^{1,4}$ \\ Stephen J. C. Hearps ${ }^{1}$ \\ Cathy Cathroppa ${ }^{1,2,3,4}$
}
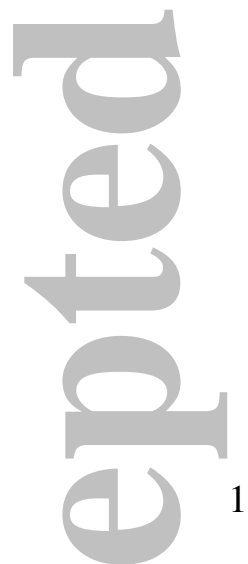

1. Clinical Sciences, Murdoch Childrens Research Institute, Parkville 3052, Australia

2. Department of Pediatrics, The University of Melbourne, Parkville 3010, Australia

3. Department of Psychology, The Royal Children's Hospital, Parkville 3052, Australia

4. Melbourne School of Psychological Sciences (MSPS), The University of Melbourne, Parkville 3010, Australia

This is the author manuscript accepted for publication and has undergone full peer review but has not been through the copyediting, typesetting, pagination and proofreading process, which may lead to differences between this version and the Version record. Please cite this article as doi:10.1002/jnr.24087. 
Abbreviated title: Neural correlates of EF post-childhood TBI

Word Count (excluding abstract and references): 4, 262

Number of Tables: 6

Number of Figures: 3

Corresponding author: Ms. Kelleynne Yu, Child Neuropsychology, c/o Murdoch Childrens Research Institute, 50 Flemington Road, Parkville 3052, Australia: Email: kelleynne.yu@mcri.edu.au

Dr. Marc Seal, Developmental Imaging, c/o Murdoch Childrens Research Institute, 50 Flemington Road, Parkville 3052, Australia: T +613 99366678 Email: marc.seal@mcri.edu.au

Mr. Jonathan Reyes, Child Neuropsychology, c/o Murdoch Childrens Research Institute, 50 Flemington Road, Parkville 3052, Australia. Email: jonathan.reyes@mcri.edu.au

Dr. Celia Godfrey, Child Neuropsychology, c/o Murdoch Childrens Research Institute, 50 Flemington Road, Parkville 3052, Australia. Email: celia.godfrey@mcri.edu.au

Prof. Vicki Anderson, Child Neuropsychology, c/o Murdoch Childrens Research Institute, 50 Flemington Road, Parkville 3052, Australia: T +613 93454679 Email: vicki.anderson@rch.org.au 
Dr. Chris Adamson, Developmental Imaging, Child Neuropsychology, c/o Murdoch Childrens Research Institute, 50 Flemington Road, Parkville 3052, Australia. Email: chris.adamson@mcri.edu.au

Mr. Nicholas Ryan, Child Neuropsychology, c/o Murdoch Childrens Research Institute, 50 Flemington Road, Parkville 3052, Australia. Email: nicholas.ryan@mcri.edu.au

Mr. Stephen Hearps, Child Neuropsychology, c/o Murdoch Childrens Research Institute, 50 Flemington Road, Parkville 3052, Australia: Email: stephen.hearps@mcri.edu.au

A/Prof. Cathy Catroppa, Child Neuropsychology, c/o Murdoch Childrens Research Institute, 50 Flemington Road, Parkville 3052, Australia: T +613 99366638 Email: cathy.catroppa@mcri.edu.au

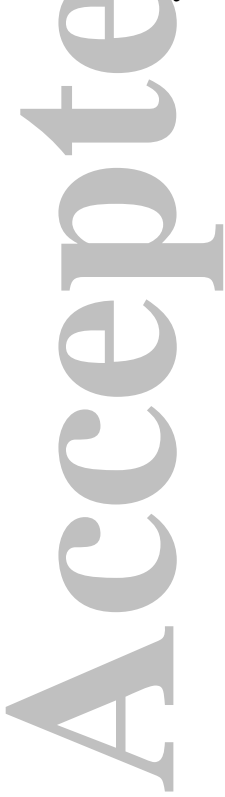




\begin{abstract}
\end{abstract}
Executive functions (EF), such as inhibition and cognitive flexibility, are essential for everyday functioning, including regulation of socially appropriate emotional responses. These skills develop during childhood and continue maturing into early adulthood. The current study aimed to investigate the very long-term impact of childhood traumatic brain injury (TBI) on inhibition and cognitive flexibility, and to examine whether global white matter is associated with these abilities. 28 young adult survivors of childhood TBI ( $M$ age at 16-year follow-up=21.67 years, $S D=2.70$ ) and 16 typically developing controls (TDCs), group-matched for age, sex and socioeconomic status, completed tests of inhibition and cognitive flexibility and underwent structural MRI. Survivors of childhood TBI did not significantly differ from TDCs on EF or white matter volume. However, the relationship between EF and white matter volumes differed between survivors of TBI and TDCs. Survivors of TBI did not mimic the brain behavior relationship that characterized EF in TDCs. The inverse brain behavior relationship, exhibited by childhood TBI survivors, suggests disruptions in the whole brain underpinning EF following childhood TBI.

Key words: traumatic brain injury, cognitive function, white matter, executive function, inhibition, cognitive flexibility, childhood.

Significance Statement: This study highlights the enduring impact that childhood traumatic brain injury can exert on survivors throughout late adolescence and into early adulthood. Survivors, who sustained traumatic brain injury in childhood, did not reflect the typical brain behavior relationship that characterized executive function in adulthood. These findings suggest long-lasting changes in the brain behavior 
connections following childhood traumatic brain injury, thereby serving as a reminder to refrain from downplaying a head injury sustained in early childhood.

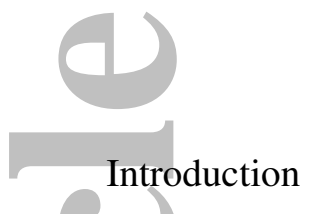

Traumatic brain injury (TBI) results from an external force to the head, which may contribute to persistent impairments in cognitive functioning (Taylor \& Alden, 1997). It is not uncommon for survivors of childhood TBI to exhibit impairments in executive functioning $(\mathrm{EF})$, referring to higher-order cognitive processes that are essential for governing complex human behavior and include attention, planning, organization, goal setting and inhibition (Anderson et al., 2001).

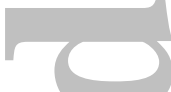

Inhibition, the ability to monitor and control responses, and cognitive flexibility, the ability to switch attention between cognitive demands (Konrad et al., 2000), are EF skills particularly vulnerable to childhood TBI (Anderson et al., 2001). Impairments in these domains have been associated with difficulties in everyday functioning, such as regulating socially appropriate emotional and behavioral responses (Beauchamp \& Anderson, 2010; Ganesalingam et al., 2007; Gioia et al., 2000).

Inhibition and cognitive flexibility emerge relatively early in childhood and show protracted development into adolescence (Anderson, 2002; Jurado \& Rosselli, 2007). Some studies have also found sex differences, with females outperforming males on measures of inhibition (Berlin \& Bohlin, 2002; Carlson \& Moses, 2001), while others have found no differences (Brocki \& Bohlin, 2004). According to the early brain vulnerability hypothesis (Dennis, 1989), sustaining a brain insult in 
childhood disrupts the acquisition of skills, particularly those in the early stages of development (Anderson et al., 2011). In keeping with this hypothesis, survivors of moderate-to-severe TBI sustained in both early (Beauchamp et al., 2011; Faber et al., 2016; Levin et al., 2004) and late childhood (Muscara et al, 2008) demonstrate impairments in inhibition and cognitive flexibility. However, the neural correlates of these difficulties remain unclear.

Importantly, healthy maturation of cortical white matter is associated with improved cognitive functioning (Kinnunen et al., 2010; Nagy et al., 2004). Ongoing processes of myelination and synaptic pruning throughout adolescence and early adulthood coincide with increasing functional specificity of neural networks that support cognitive functioning (Asato et al., 2010; Hwang et al., 2010). Multiple studies have reported disruptions in these neural processes following diffuse axonal injury (DAI), which results from shearing of white matter connecting pathways within neural networks associated with cognitive flexibility and inhibition (Beauchamp et al., 2011; Berryhill et al., 1995; Kinnunen et al., 2010; Levin et al., 2004; Ryan et al., 2013; Tasker, 2006). Perhaps not surprisingly, these childhood injuries are associated with widespread morphological changes, including reductions in cortical gray and white matter, as well as overall reductions in brain volume (Beauchamp et al., 2011; Benson et al., 2007; Bigler, 2001; Bigler, 2007; Ding et al., 2008; Gale et al., 2005; Trivedi et al., 2007; Wilde et al., 2005).

Although previous reports establish a link between persisting impairments in inhibition, cognitive flexibility, and white matter volume reductions in pediatric TBI (Faber et al., 2016; Kurowski et al., 2009), the neural correlates of long-term outcomes in this domain are poorly characterized. For instance, no study to date has 
investigated the possible link between white matter volume and inhibition and cognitive flexibility in the long-term post-childhood TBI.

The overall aim of the present study is to investigate the presence of global white matter macrostructural abnormalities following childhood TBI and examine their relationship with concurrent measures of EF. More specifically, the study aimed to: (i) examine whether inhibition and cognitive flexibility deficits persist to 16 years after childhood TBI; (ii) determine whether cortical white matter volume may explain variability in EF performance 16 years post-injury and; (iii) investigate the brain behavior relationship underlying cortical white matter volume and inhibition and cognitive flexibility in survivors of childhood TBI and typically developing controls (TDCs).

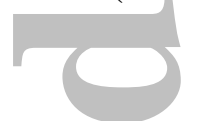

We hypothesized that, for survivors of childhood TBI (i) inhibition and cognitive flexibility would be reduced compared to TDCs; (ii) cortical white matter volumes would be significantly smaller than TDCs and; (iii) larger cortical white matter volumes would predict better performance on tasks of inhibition and cognitive

flexibility in both childhood TBI survivors and TDCs. 


\section{Method}

\section{Participants}

The study reports on a sample of English-speaking children who had sustained early childhood TBI between 1993 and 1997 and an age matched typically developing control group. As part of a larger prospective longitudinal study, participants were originally recruited upon admission to the Emergency Department or Pediatric Intensive Care Unit at The Royal Children's Hospital (RCH, Melbourne, Australia) (Anderson et al., 2000), and evaluated at several time points: 0-3 (acute), 6, 12, and 30 months, and 5 and 10 years post-injury.

Inclusion criteria of the original study were: (1) age at injury between 1 and 7

years; (2) documented evidence of TBI, including a period of altered consciousness and; (3) comprehensive medical records that allow ascertainment of injury severity. Exclusion criteria were: (1) penetrating or inflicted head injury; (2) history of previous closed head injury and; (3) pre-existing physical, neurological, psychiatric or developmental disorders.

Twenty-eight young adults (12 males, $M$ age at injury=5.04 years range=5.91, $S D=1.79 ; M$ age at 16 -year follow-up=21.67 years, $S D=2.70$ range=8.75), comprising $29 \%$ of the original TBI sample consented to participate in the 16-year follow-up assessment and has usable MRI scan data. The control group consisted of 16 healthy young adults (11 males, $M$ age at 16-year follow-up=21.11 years, $S D=2.30$ ), $46 \%$ of the original control sample, who were matched with the original TBI sample on age, socioeconomic status and sex, and has usable MRI scan data at the 16-year follow-up. 
Participants with TBI were categorized into groups according to their level of injury severity, using a combination of measures including the Glasgow Coma Score (GCS: Teasdale \& Jennett, 1974), and the existence of radiological and neurological abnormalities. Injury severity was classified at study recruitment as follows: (1) mild TBI (n=7): GCS 13 to 15 , no mass lesion on CT/MRI scans, and no neurologic deficits; (2) moderate TBI ( $n=15)$ : GCS 9 to 12; and/or mass lesion or other evidence of specific injury on CT/MRI, and/or neurological impairment and; (3) severe TBI (n=6): GCS 3 to 8, with mass lesion or other evidence of specific injury on CT/MRI, and/or neurological impairment. However, given small and uneven sample sizes across the TBI subgroups, TBI participants were combined for analysis and compared to the control group.

\section{Measures at 16-year follow-up}

Socio-economic Status. Using Daniel's Scale of Occupational Prestige (Daniel, 1983), socio-economic status (SES), understood as one's social standing, was obtained on recruitment. Socio-economic status was operationalized using parents' occupation, which was rated on a 7-point scale from 1.0 to 7.0 with higher scores delineating lower socioeconomic status.

Cognitive Abilities. The Wechsler Abbreviated Scale of Intelligence two subtest form (WASI, Wechsler, 2011) was administered to assess intellectual ability, which was also known as the Full Scale Intelligence Quotient (FSIQ) ( $M=100$, $S D=15)$.

Executive Function. The Delis-Kaplan Executive Function System (D-KEFS) (Delis, Kaplan, \& Kramer, 2001) Color-Word Interference Test (CWIT), which was a modification of the original Stroop (1935) task, consists of four time-limited tasks 
$(M=10, S D=3)$.

(1) Color Naming: The examinee is shown rows of individual patches of different colors and is asked to name the color of the patches as quickly as possible.

(2) Word Reading: The examinee is shown rows of words printed in black ink and is asked to read the words as quickly as possible.

(3) Inhibition: The examinee is shown rows of words printed in dissonant ink colors and is asked to say the color of the ink the words are printed in, and not read the words, as quickly as possible.

(4) Inhibition/Switching: The examinee is shown rows of words printed in dissonant ink colors and some of the words are contained within rectangles. Similar to the previous task, the examinee is asked to say the color of the ink the words are printed in. However, if the word is enclosed within a rectangle, the examinee is asked to read the word instead of saying the color. This task was to be done as quickly as possible.

The initial two tasks served as baseline low-level cognitive measures while the third and fourth tasks tapped into high-level cognitive function - inhibition and cognitive flexibility. Of note, performance on the latter two tasks was likely to be confounded by other factors such as fatigue and basic processing speed (Lansbergen et al., 2007). Therefore, in order to accurately isolate any deficits in higher-level cognitive tasks over and above lower-level cognitive functioning, pure measures of inhibition and cognitive flexibility were obtained by using contrast scores $(M=10 ; S D=3)$ : inhibition 
(inhibition minus color naming completion time), inhibition/cognitive flexibility (inhibit/switching minus color naming completion time) and cognitive flexibility (inhibit/switching minus inhibit completion time) (Delis et al., 2001). Using differences in performance between high-level and baseline tasks is consistent with prevailing methods of assessing inhibition on Stroop tasks (Lansbergen et al., 2007; Thornton et al., 2007). In addition, these contrast scores share moderate intercorrelations with their respective tasks, lending validity to these measures (Delis et al., 2001).

MRI Scans. Imaging data were acquired on a 3T Siemens TIM Trio scanner (Erlangen, Germany) at the Murdoch Childrens Research Institute, at the RCH. As part of the follow-up protocol, a high-resolution anatomical T1 scan (3D MPRAGE) was obtained; $\mathrm{TR}=1900 \mathrm{~ms}, \mathrm{TE}=2.62 \mathrm{~ms}$, matrix size $=250 \times 250,176$ contiguous sagittal slices, isotropic voxel dimensions $=0.8 \times 0.8 \times 0.8 \mathrm{~mm}$. Morphological measurements of gray and white matter from T1-weighed MR images were acquired using automated segmentation and cortical parcellation tools in FreeSurfer version 5.3.X (Van Essen et al., 2012). This procedure involved motion correction, intensity normalisation, automated topology corrections, and automatic segmentations of gray and white matter. The cortex was parcellated and labelled into to 128 Regions of Interest (74 per hemisphere) using the Destrieux atlas (Destrieux et al., 2010). Quality assurance and manual editing of segmentation defects was performed using tkmedit, a FreeSurfer volume editing tool, after processing by an experienced image analyst (CA). Reprocessing was performed if required. 


\section{Procedure}

This study was approved by the RCH Human Research Ethics Committee (HREC \#36004). For the current 16-year follow-up study, all participants were re-contacted by mail and provided with a description of the current study. Informed consent was obtained prior to neuropsychological assessment and MRI brain scan. Assessments were conducted by trained psychologists.

\section{Statistical Analyses}

Volumetric, demographic and cognitive data were combined using R Studio Version 0.98.1091. All data was entered and checked for violations of normality in SPSS Version 21.0. Thereafter, descriptive and inferential analyses were conducted. Effect sizes were calculated using Hedges's $g$ and Cramer's $V$. Effect sizes less than .20 were small, effect sizes of .50 were classified as moderate, and effect sizes above .80 were considered large (Sullivan \& Feinn, 2012). Independent samples $t$-tests were conducted to compare (i) injury age, SES and FSIQ between participating and nonparticipating samples; (ii) age at 16-year follow-up, SES, and FSIQ between participating TBI participants and controls and; (iii) EF and volumetric measures. Analysis of variance analyses were also conducted to check for differences in EF and volumetric measures by severity. Post-hoc Tukey HSD tests were conducted for all significant omnibus F tests. Pearson chi-squared tests analyzed group differences for categorical variables such as sex. A series of hierarchical regression analyses was conducted to investigate whether the inclusion of variables would best predict EF performance. Prior to conducting the regression analyses, data was screened for multicollinearity and no single data point was observed to excessively influence the models and parameter estimates. As sex and age were found to impact EF 
performance, these variables were included as covariates. While controlling for age at 16-year follow-up and sex, the impact of group, cortical white matter and interaction of group and cortical white matter was added in successive steps. As per conventional practice, estimated cortical white and gray matter volumes were corrected for total intracranial volume (ICV) (Fischl et al., 2004). Total ICV was used to control for inter-subject variability in white and gray matter volume. Given the small sample size, SES and FSIQ at 16-year follow-up were excluded from the present analyses.

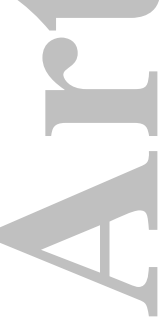

\section{Results}

Participants and non-participants were compared to assess whether the present sample

was representative of the original TBI and control cohort. No statistically significant differences were observed between the participating and non-participating control cohort. The participating TBI cohort at 16-year follow-up included fewer males $\chi^{2}(1$, $N=12)=4.72, p=.030$, and presented with lower SES, $(M=4.63, S D=0.98), t(62)=-2.08$, $p=.042$, compared to the non-participating TBI sample. No statistically significant differences were observed within the TBI cohort for age at injury and FSIQ. Demographic characteristics of the final sample indicated no statistically significant differences in sex and age at the 16-year follow-up (see Table 1). However, FSIQ and SES differed significantly between TBI participants and controls, with controls presenting with higher SES and FSIQ.

Insert Table 1 here 
Descriptive statistics of EF and volumetric measures for TBI and control participants are presented in Table 2. Boxplots depicting normal distributions of executive function measures and cortical white matter are displayed (see Supplementary Materials Figure 1 and 2). No statistically significant differences were observed between childhood TBI participants and controls on any of the EF or volumetric measures. Differences on EF and volumetric measures across TBI severity subgroups

are presented in Table 3. The independent between-groups analysis of variance yielded a statistically significant effect for cognitive flexibility only. The Tukey HSD post-hoc test indicated that the cognitive flexibility mean score for the mild TBI subgroup $(M=11.29, S D=2.56)$ was significantly better than the cognitive flexibility mean score for moderate TBI subgroup $(M=7.60, S D=2.20)$. All other comparisons were not significant.

Insert Table $2 \& 3$ here

\section{Predictors of EF performance at 16-year follow-up}

A 4-step hierarchical multiple regression, which involved adding variables at each successive stage, was performed to investigate predictors- group and cortical white matter of EF performance 16 years following childhood TBI. Age at 16-year followup and sex were entered at step 1 to control for age and sex effects. Group was entered in step 2 and cortical white matter volume was entered in step 3. The interaction between group and cortical white matter was entered in step 4. The variables were entered in this order to determine whether the interaction between 
group and cortical white matter volume would explain the variation on the EF measure over and above group and cortical white matter separately. Analysis was conducted separately for inhibition (see Table 4), cognitive flexibility (see Table 5) and inhibition/cognitive flexibility (see Table 6).

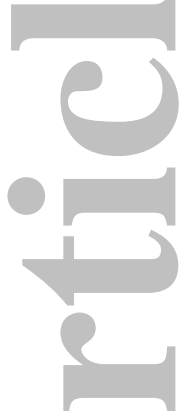

Insert Table 4, $5 \& 6$ here

The models for inhibition and cognitive flexibility as separate measures were nonsignificant. However, the overall model predicting inhibition/cognitive flexibility measure was statistically significant. Group and cortical white matter were found to have significant main effects on inhibition/cognitive flexibility. A significant interaction effect of group by cortical white matter was also observed for inhibition/cognitive flexibility (illustrated in Figure 1).

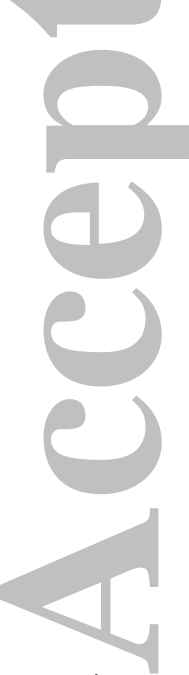

Insert Figure 1 here

\section{Discussion}

The overarching aim of the present study was to investigate the very long-term impact of childhood TBI on EF and to determine whether white matter macrostructural abnormalities following childhood TBI may relate to EF performance. Study findings provided partial support for expectations. In accordance with the early brain vulnerability hypothesis (Anderson et al., 2011), sustaining an 
early childhood TBI disrupts the maturation of skills in the early stages of development. In the present study, at a group level, EF abilities and global volumetric measures did not differ between survivors of childhood TBI and TDCs. However, evaluation of brain behavior relationships in the TBI and control groups showed that the direction of the association differed as a function of group membership.

The hypothesis that, at 16-years post-injury, childhood TBI survivors will demonstrate impaired inhibition and cognitive flexibility skills in comparison to controls was not supported. In order to disentangle higher order EF, that is, inhibition and cognitive flexibility abilities, from basic processing skills (e.g., color naming), contrast measures were derived based on performance on the CWIT in the present study (Delis et al., 2001). In contrast, Faber et al. (2016) and Muscara et al. (2008) operationalized inhibition and cognitive flexibility abilities by taking completion time and total number of errors on the CWIT inhibition and inhibition/switching tasks. Of note, there were suggestions that EF deficits in childhood TBI survivors may be confounded by impaired processing speed (Ginstfeldt \& Emanuelson, 2010; Konig et al., 2015). Therefore, the removal of baseline processing skills in the current study may explain the discrepant findings. Nonetheless, it was worth noting that completion time of all four CWIT tasks did not differ between TBI survivors and their typicallydeveloping peers.

The hypothesis that, at 16-year follow-up, childhood TBI survivors will demonstrate smaller white matter volumes than TDCs, was also not supported. Rather, TBI survivors exhibited comparable white matter volumes to their healthy peers. Notably, white matter shearing is most commonly observed following moderate to severe TBI (Oni et al., 2010; Tasker, 2006; Wilde et al., 2005). Given the small sample of severe TBI participants $(n=6)$ in the present study, childhood TBI 
severity groups were combined and investigated as a single group. As a result, caution is warranted in making inferences regarding the very long-term impact of severe childhood TBI on global indices of white matter volume.

Our expectation of a link between cortical white matter and inhibition and cognitive flexibility abilities, was partially supported. This relationship was not observed for inhibition and cognitive flexibility when these skills were investigated as separate measures. However, a significant brain behavior relationship was observed for a composite measure of inhibition and cognitive flexibility skills. Consistent with previous literature (Brickman et al., 2006; Konrad et al., 2013), better EF abilities were associated with larger white matter volumes in the typically developing control group. In contrast, survivors of TBI demonstrated an inverse brain behavior relationship, whereby smaller white matter volumes were linked to better EF.

Overall, these findings suggest that in the long-term following childhood TBI, brain behavior relationships do not mimic those observed in typically developing young adults. In keeping with the early brain vulnerability hypothesis (Dennis, 1989), this differential brain behavior relationship may suggest possible disruption in the whole brain underpinning EF following childhood TBI (Chapman \& Mckinnon, 2000). In fact, our findings indicate diffuse rather than localized brain changes, in keeping with the nature of acute brain pathology associated with TBI.

Clinical implications

Previous reports show that children with TBI exhibit impairments in EF (Taylor \& Alden, 1997). For instance, survivors of childhood TBI with inhibition deficits demonstrate difficulties regulating appropriate behavioral responses (Beauchamp, \& Anderson, 2010). At present, the childhood TBI research has 
demonstrated the persistence of EF deficits up to 10 years post-injury (Faber et al., 2016; Muscara et al., 2008). The present study has informed the childhood TBI research further by demonstrating the very long-term impact of 16-year childhood TBI on EF abilities. Specifically, childhood TBI survivors did not mimic the healthy brain behavior relationship underpinning inhibition and cognitive flexibility abilities.

Evidence for inverse pattern of brain behavior relationships in the childhood TBI group may be suggestive of long-term changes to their neural architecture arising from their injury. Processes of myelination and synaptic pruning, that occur during childhood and adolescence, have been known to ensure efficient neural functioning (Blakemore \& Choudhury, 2006). Importantly, disruption of synaptic pruning processes was found to maintain extraneous neural connections within the brain following pediatric TBI (Mychasiuk et al., 2015). Indeed, disrupted synaptic pruning was observed in childhood TBI survivors who demonstrated increased cortical thickness despite exhibiting poorer behavioural control (Wilde et al., 2012). Therefore, the inverse brain behavior relationship observed in childhood TBI survivors in our study (i.e. greater white matter was associated with poorer EF) suggests that sustaining TBI in childhood may disrupt or delay processes of synaptic pruning. Nonetheless, this mechanism warrants further investigation and it is in the interest of future research to investigate changes in gray matter in relation to EF abilities following long-term childhood TBI.

Most recently, reduced white matter integrity of the frontal lobes, particularly the ventral striatum has been linked to impaired EF in long-term childhood TBI survivors (Faber et al., 2016; Zappala et al., 2011). Indeed, the frontal lobes rest against the rough interior of the skull, rendering it more susceptible to damage following an injury to the head (Bigler, 2007). For this reason, sustaining a childhood TBI likely 
altered the white matter integrity underpinning childhood TBI survivors' EF abilities. Nonetheless, it was important to note that the observed relationship between white matter volume and EF in the present study does not imply causation. At this stage, further attention into the white matter integrity of childhood TBI survivors' brains, particularly their frontal lobes, will assist in understanding the link between childhood TBI and its long-term impact on EF.

\section{Limitations and future directions}

MRI used in the current study was useful in providing volumetric white matter as an index of DAI. However, volumetric MRI was unable to demarcate the white matter integrity of survivors of childhood TBI and healthy adults. In fact, research that employed DTI has revealed lasting changes in white matter connections following childhood TBI (Wozniak et al., 2007; Yuan et al., 2007). Of note, it was particularly useful to utilize DTI with mild childhood TBI survivors, given that their brain abnormalities often went undetected on conventional MRI scans (Shenton et al., 2012). Therefore, it was recommended that future studies utilize more sensitive neuroimaging techniques (e.g. DTI) to investigate changes in white matter integrity in supporting the EF capabilities of long-term survivors of childhood TBI.

Another limitation relating to the present study was sample size. Given the small sample size, the three severity TBI subgroups (i.e. mild, moderate \& severe) were combined to investigate the impact of TBI, potentially masking any severity effects. According to a recent systematic review, EF abilities differed across severity groups, and moderate childhood TBI survivors were more likely to display EF-related difficulties at follow-up compared to mild childhood TBI survivors (Lloyd et al., 2015). Of note, EF deficits were most apparent in past studies that compared across 
severity subgroups (Nadebaum et al., 2007; Treble-Barna et al., 2016), and between moderate-to-severe childhood TBI survivors and typically developing peers (Cooper et al., 2014; Faber et al., 2016; Levin et al., 2004; Muscara et al., 2008). Taken together, it was possible that EF deficits, if any, following from more severe childhood TBI, may have been concealed in the present study. Given the small sample size, the current study was also unable to investigate sex differences in brain volumes and measures of inhibition and cognitive flexibility.

A final limitation was that only specific aspects of EF, namely inhibition and cognitive flexibility, were investigated in the present study. Previous studies demonstrating lasting EF deficits following childhood TBI have examined various EF domains, such as attention, goal setting, inhibition and cognitive flexibility. For instance, goal setting was found to be selectively impaired 10 years following childhood TBI (Beauchamp et al., 2011). As inhibition and cognitive flexibility have been understood to be the earliest EF domains to mature (Anderson, 2002; Huizinga et al., 2006), it was possible that these selective EF skills were more resilient to disruption following childhood TBI. Nonetheless, this account alone cannot fully explain the EF skills demonstrated by survivors of childhood TBI in the present study. Given that 16 years have passed since initial injury, childhood TBI survivors' EF skills likely reflected an intricate interplay of their recovery from injury coupled with their ongoing cognitive development. For that reason, it was recommended that future research strive to disentangle processes of recovery from long-term childhood TBI from those that characterize typical cognitive development. 


\section{Conclusion}

This is the first prospective longitudinal study to demonstrate the presence of neural abnormalities underpinning EF skills following TBI sustained in childhood. To our knowledge, this study reports on the largest cohort of survivors of childhood TBI assessed longitudinally over a 16-year period. The current findings revealed that that impact of childhood TBI coupled with cortical white matter explained EF abilities in early adulthood. Importantly, the neural architecture underpinning EF abilities was disparate between childhood TBI survivors and healthy adults. In healthy adults, inhibition and cognitive flexibility improved with increased cortical white matter. In contrast, childhood TBI survivors exhibited an inverse relationship between inhibition/cognitive flexibility abilities and cortical white matter. The use of more sensitive neuroimaging techniques in future studies is encouraged to uncover the presence of subtle white matter abnormalities in childhood TBI survivors and its relationship to cognitive outcomes.

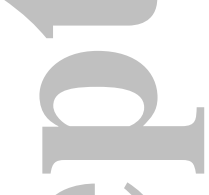

Acknowledgement: This research was conducted within the Child Neuropsychology and Developmental Imaging research groups, Murdoch Childrens Research Institute, Victoria. This work was funded through research grants awarded by the Victorian Neurotrauma Initiative and Victorian Government's Operational Infrastructure Support Program.

Conflict of Interest Statement: All authors declare no conflict of interest. 
Role of Authors: All authors had full access to all the data in the study and take responsibility for the integrity of the data and the accuracy of data analysis. Study concept and design: K.Y., M.L.S., J.R., C.G., V.A., \& C.C. Acquisition of data: C.G., M.L.S., \& C.A. Statistical analysis and interpretation of data: K.Y., M.L.S., N.P.R., \& S.J.C.H. Drafting of the manuscript: K.Y., M.L.S., J.R., C.G., V.A., N.P.R., S.J.C.H., \& C.C. Critical revision of the manuscript for important intellectual content: C.G., V.A., \& C.C. Obtained funding: V.A. Administrative, technical and material support:

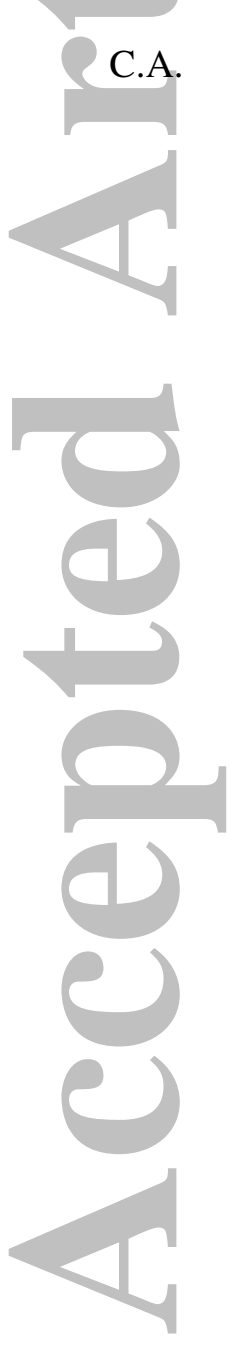




\section{References}

Anderson, P. (2002). Assessment and development of executive function (EF) during childhood. Child Neuropsychology, 8(2), 71-82.

Anderson, V. A., Anderson, P., Northam, E., Jacobs, R., \& Catroppa, C. (2001). Development of executive functions through late childhood and adolescence in an Australian sample. Developmental Neuropsychology, 20(1), 385-406.

Anderson, V. A., Catroppa, C., Rosenfeld, J., Haritou, F., \& Morse, S. A. (2000). Recovery of memory function following traumatic brain injury in pre-school children. Brain Injury, 14(8), 679-692.

Anderson, V., Spencer-Smith, M., \& Wood, A. (2011). Do children really recover better? Neurobehavioural plasticity after early brain insult. Brain, awr103.

Asato, M. R., Terwilliger, R., Woo, J., \& Luna, B. (2010). White matter development in adolescence: a DTI study. Cerebral Cortex, 20(9), 2122-2131.

Beauchamp, M., \& Anderson, V. (2010). SOCIAL: An integrative framework for the development of social skills. Psychological Bulletin, 136(1), 39.

Beauchamp, M., Catroppa, C., Godfrey, C., Morse, S., Rosenfeld, J.V., \& Anderson, V. (2011). Selective changes in executive functioning ten years after severe childhood traumatic brain injury. Developmental neuropsychology, 36(5), 578-595. 
Beauchamp, M. H., Ditchfield, M., Maller, J. J., Catroppa, C., Godfrey, C., Rosenfeld, J. V., Kean, M. J., \& Anderson, V. A. (2011). Hippocampus, amygdala and global brain changes 10 years after childhood traumatic brain injury. International Journal of Developmental Neuroscience, 29(2), 137-143.

Benson, R. R., Meda, S. A., Vasudevan, S., Kou, Z., Govindarajan, K. A., Hanks, R.

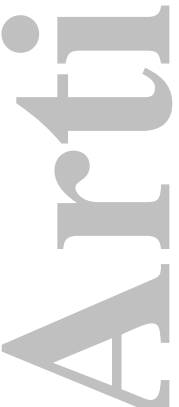

A., Millis, S. R., Makki, M., Latif, Z., Coplin, W., Meythaler, J., \& Haacke, E. M. (2007). Global white matter analysis of diffusion tensor images is predictive of injury severity in traumatic brain injury. Journal of Neurotrauma, 24(3), 446-459.

Berlin, L., \& Bohlin, G. (2002). Response inhibition, hyperactivity, and conduct problems among preschool children. Journal of Clinical Child and Adolescent Psychology, 31(2), 242-251.

Berryhill, P., Lilly, M. A., Levin, H. S., Hillman, G. R., Mendelsohn, D., Brunder, D. G., Fletcher, J. M., Kufera, J., Kent, T. A., Yeakley, J., Bruce, D., \& Eisenberg, H. M. (1995). Frontal lobe changes after severe diffuse closed head injury in children: a volumetric study of magnetic resonance imaging. Neurosurgery, 37(3), 392-400.

Bigler, E. D. (2001). Quantitative magnetic resonance imaging in traumatic brain injury. The Journal of Head Trauma Rehabilitation, 16(2), 117-134.

Bigler, E. D. (2007). Anterior and middle cranial fossa in traumatic brain injury: relevant neuroanatomy and neuropathology in the study of neuropsychological outcome. Neuropsychology, 21(5), 515. 
Blakemore, S. J., \& Choudhury, S. (2006). Development of the adolescent brain: implications for executive function and social cognition. Journal of Child Psychology and Psychiatry, 47(3-4), 296-312.

Brickman, A. M., Zimmerman, M. E., Paul, R. H., Grieve, S. M., Tate, D. F., Cohen, R. A., Williams, L. M., Clark, C. R., \& Gordon, E. (2006). Regional white matter and neuropsychological functioning across the adult lifespan. Biological Psychiatry, 60, 444-453.

Brocki, K. C., \& Bohlin, G. (2004). Executive functions in children aged 6 to 13: A dimensional and developmental study. Developmental Neuropsychology, 26(2), 571-593.

Carlson, S. M., \& Moses, L. J. (2001). Individual differences in inhibitory control and children's theory of mind. Child Development, 72(4), 1032-1053.

Chapman, S. B., \& Mckinnon, L. (2000). Discussion of developmental plasticity: Factors affecting cognitive outcome after pediatric traumatic brain injury. Journal of Communication Disorders, 33(4), 333-344.

Cooper, J. M., Catroppa, C., Beauchamp, M. H., Eren, S., Godfrey, C., Ditchfield, M., \& Anderson, V. A. (2014). Attentional control ten years post-childhood traumatic brain injury: the impact of lesion presence, location, and severity in adolescence and early adulthood. Journal of neurotrauma, 31(8), 713-721.

Daniel, A. (1983). Power, Privilege and Prestige: Occupations in Australia. Longman-Chesire: Melbourne. 
Destrieux, C., Fischl, B., Dale, A., \& Halgren, E. (2010). Automatic parcellation of human cortical gyri and sulci using standard anatomical nomenclature. Neuroimage, 53(1), 1-15.

Delis, D. C., Kaplan, E., \& Kramer, J. H. (2001). Delis-Kaplan executive function system (D-KEFS). Psychological Corporation.

Ding, K., de la Plata, C. M., Wang, J. Y., Mumphrey, M., Moore, C., Harper, C., Madden, C. J., McColl, R., Whittemore, A., Devous, M. D., \& Diaz-Arrastia, R. (2008). Cerebral atrophy after traumatic white matter injury: correlation with acute neuroimaging and outcome. Journal of Neurotrauma, 25(12), $1433-1440$.

Faber, J., Wilde, E. A., Hanten, G., Ewing-Cobbs, L., Aitken, M. E., Yappampalli, R., (1) MacLeod, M. C., Mullin, S. H., Chu, Z. D., Li, X., Hunter, J. V., NobleHaeusslein, L., \& Levin, H. S. (2016). Ten-year outcome of early childhood traumatic brain injury: Diffusion tensor imaging of the ventral striatum in relation to executive functioning. Brain Injury, 28, 1-7.

Fischl, B., Van Der Kouwe, A., Destrieux, C., Halgren, E., Ségonne, F., Salat, D. H., Busa, E., Seidman, L. J., Goldstein, J., Kennedy, D., Caviness, V., Makris, N., Rosen, B., \& Dale, A. M. (2004). Automatically parcellating the human cerebral cortex. Cerebral Cortex, 14(1), 11-22.

Gale, S. D., Baxter, L., Roundy, N., \& Johnson, S. C. (2005). Traumatic brain injury and grey matter concentration: a preliminary voxel based morphometry study. Journal of Neurology, Neurosurgery \& Psychiatry, 76(7), 984-988. 
Ganesalingam, K., Yeates, K. O., Sanson, A., \& Anderson, V. (2007). Social problem-solving skills following childhood traumatic brain injury and its association with self-regulation and social and behavioural functioning. Journal of Neuropsychology, 1(2), 149-170.

Gioia, G. A., Isquith, P. K., Guy, S. C., \& Kenworthy, L. (2000). Test review behavior rating inventory of executive function. Child Neuropsychology, 6(3), 235-238.

Huizinga, M., Dolan, C. V., \& van der Molen, M. W. (2006). Age-related change in executive function: Developmental trends and a latent variable analysis. Neuropsychologia, 44(11), 2017-2036.

Hwang, K., Velanova, K., \& Luna, B. (2010). Strengthening of top-down frontal (1) cognitive control networks underlying the development of inhibitory control: a functional magnetic resonance imaging effective connectivity study. The Journal of Neuroscience, 30(46), 15535-15545.

Jurado, M. B., \& Rosselli, M. (2007). The elusive nature of executive functions: a review of our current understanding. Neuropsychology Review, 17(3), 213233.

Kinnunen, K. M., Greenwood, R., Powell, J. H., Leech, R., Hawkins, P. C., Bonnelle, V., Patel, M. C., Counsell, S. J., \& Sharp, D. J. (2010). White matter damage and cognitive impairment after traumatic brain injury. Brain, 134(2), 449-463.

Konrad, K., Firk, C., \& Uhlhaas, P. J. (2013). Brain development during adolescence. Deutsches Arzeteblatt International, 110(25), 425-31. 
Konrad, K., Gauggel, S., Manz, A., \& Schöll, M. (2000). Inhibitory control in children with traumatic brain injury (TBI) and children with attention deficit/hyperactivity disorder (ADHD). Brain Injury, 14(10), 859-875.

Kurowski, B., Wade, S. L., Cecil, K. M., Walz, N. C., Yuan, W., Rajagopal, A., \& Holland, S. K. (2009). Correlation of diffusion tensor imaging with executive function measures after early childhood traumatic brain injury. Journal of Pediatric Rehabilitation Medicine, 2(4), 273-283.

Lansbergen, M. M., Kenemans, J. L., \& Van Engeland, H. (2007). Stroop interference and attention-deficit/hyperactivity disorder: a review and meta-analysis. Neuropsychology, 21(2), 251.

Levin, H. S., Hanten, G., Zhang, L., Swank, P. R., \& Hunter, J. (2004) Selective impairment of inhibition after TBI in children. Journal of Clinical and Experimental Neuropsychology, 25(5), 589-597.

Lloyd, J., Wilson, M. L., Tenovuo, O., \& Saarijärvi, S. (2015). Outcomes from mild and moderate traumatic brain injuries among children and adolescents: A systematic review of studies from 2008-2013. Brain Injury, 29(5), 539-549.

Muscara, F., Catroppa, C., \& Anderson, V. (2008). The impact of injury severity on executive function 7-10 years following pediatric traumatic brain injury. Developmental Neuropsychology, 33(5), 623-636.

Mychasiuk, R., Hehar, H., Ma, I., Kolb, B., \& Esser, M. J. (2015). The development of lasting impairments: A mild pediatric brain injury alters gene expression, dendritic morphology, and synaptic connectivity in the prefrontal cortex of rats. Neuroscience, 288, 145-155. 
Nadebaum, C., Anderson, V., \& Catroppa, C. (2007). Executive function outcomes following traumatic brain injury in young children: A five year follow-up. Developmental Neuropsychology, 32(2), 703-728.

Nagy, Z., Westerberg, H., \& Klingberg, T. (2004). Maturation of white matter is associated with the development of cognitive functions during childhood. Journal of Cognitive Neuroscience, 16(7), 1227-1233.

Oni, M. B., Wilde, E. A., Bigler, E. D., McCauley, S. R., Wu, T. C., Yallampalli, R., Chu, Z., Li, X., Hunter, J. V., Vasquez, A C., \& Levin, H. S. (2010). Diffusion tensor imaging analysis of frontal lobes in pediatric traumatic brain injury. Journal of Child Neurology, 25(8), 976-984.

Ryan, N. P., Anderson, V., Godfrey, C., Beauchamp, M. H., Coleman, L., Eren, S., (1) Rosema, S., Taylor, K., \& Catroppa, C. (2014). Predictors of very-long-term sociocognitive function after pediatric traumatic brain injury: evidence for the vulnerability of the immature "social brain". Journal of Neurotrauma, 31(7), $649-657$.

Shenton, M. E., Hamoda, H. M., Schneiderman, J. S., Bouix, S., Pasternak, O., Rathi, Y., Vu, M. A., Purohit, M. P., Helmer, K., Koerte, I., Lin, A. P. (2012). A review of magnetic resonance imaging and diffusion tensor imaging findings in mild traumatic brain injury. Brain imaging and behavior, 6(2), 137-192.

Stroop, J. R. (1935). Studies of interference in serial verbal reactions. Journal of Experimental Psychology, 18(6), 643.

Sullivan, G. M., \& Feinn, R. (2012). Using effect size-or why the P value is not enough. Journal of Graduate Medical Education, 4(3), 279-282. 
Tasker, R. C. (2006). Changes in white matter late after severe traumatic brain injury in childhood. Developmental Neuroscience, 28, 302-308.

Taylor, H. G., \& Alden, J. (1997). Age-related differences in outcomes following childhood brain insults: an introduction and overview. Journal of the International Neuropsychological Society, 3(06), 555-567.

Teasdale, G., \& Jennett, B. (1974). Assessment of coma and impaired consciousness: A practical scale. The Lancet, 304(7872), 81-84.

Thornton, W. L., Shapiro, R. J., Deria, S., Gelb, S., \& Hill, A. (2007). Differential impact of age on verbal memory and executive functioning in chronic kidney disease. Journal of the International Neuropsychological Society, 13(02), 344353.

Treble-Barna, A., Zang, H., Zhang, N., Taylor, H. G., Yeates, K. O., Wade, S. (2016). Long-term neuropsychological profiles and their role as mediators of adaptive functioning after traumatic brain injury in early childhood. Journal of Neurotrauma, 33, 1-10.

Trivedi, M. A., Ward, M. A., Hess, T. M., Gale, S. D., Dempsey, R. J., Rowley, H. A., \& Johnson, S. C. (2007). Longitudinal changes in global brain volume between 79 and 409 days after traumatic brain injury: relationship with duration of coma. Journal of Neurotrauma, 24(5), 766-771.

Van Essen, D. C., Glasser, M. F., Dierker, D. L., Harwell, J., \& Coalson, T. (2012). Parcellations and hemispheric asymmetries of human cerebral cortex analyzed on surface-based atlases. Cerebral Cortex, 22(10), 2241-2262. 
Wechsler, D. (2011). Wechsler Abbreviated Scale of Intelligence - Second Edition. San Anotonio, TX: The Psychological Corporation.

Wilde, E. A., Hunter, J. V., Newsome, M. R., Scheibel, R. S., Bigler, E. D., Johnson, J. L., Fearing, M. A., Cleavinger, H. B., Li, X., Swank, P. R., Pedroza, C., Roberson, G. S., Bachevalier, J., \& Levin, H. S. (2005). Frontal and temporal morphometric findings on MRI in children after moderate to severe traumatic brain injury. Journal of Neurotrama, 22(3), 333-344.

Wilde, E. A., Merkley, T. L., Bigler, E. D., Max, J. E., Schmidt, A. T., Ayoub, K. W., McCauley, S. R., Hunter, J. V., Hanten, G., Li, X., Chu, Z. D., \& Levin, H. S. (2012). Longitudinal changes in cortical thickness in children after traumatic brain injury and their relation to behavioral regulation and emotional control. International journal of developmental neuroscience, 30(3), 267-276.

Wozniak, J. R., Krach, L., Ward, E., Mueller, B. A., Muetzel, R., Schnoebelen, S., Kiragu, A., \& Lim, K. O. (2007). Neurocognitive and neuroimaging correlates of pediatric traumatic brain injury: a diffusion tensor imaging (DTI) study. Archives of Clinical Neuropsychology, 22(5), 555-568.

Yuan, W., Holland, S. K., Schmithorst, V. J., Walz, N. C., Cecil, K. M., Jones, B. V., Karunanayaka, P., Michaud, L., \& Wade, S. L. (2007). Diffusion tensor MR imaging reveals persistent white matter alteration after traumatic brain injury experienced during early childhood. American Journal of Neuroradiology, 28(10), 1919-1925. 
Zappala, G., de Schotten, M. T., \& Eslinger, P. J. (2012). Traumatic brain injury and the frontal lobes: what can we gain with diffusion tensor imaging?. Cortex,

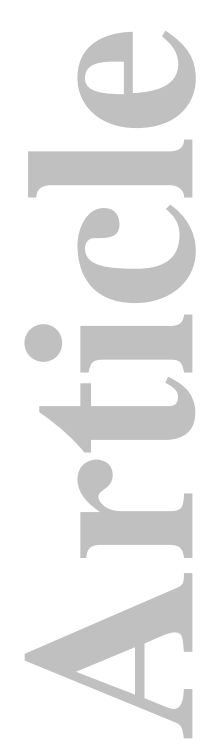
$48(2), 156-165$.

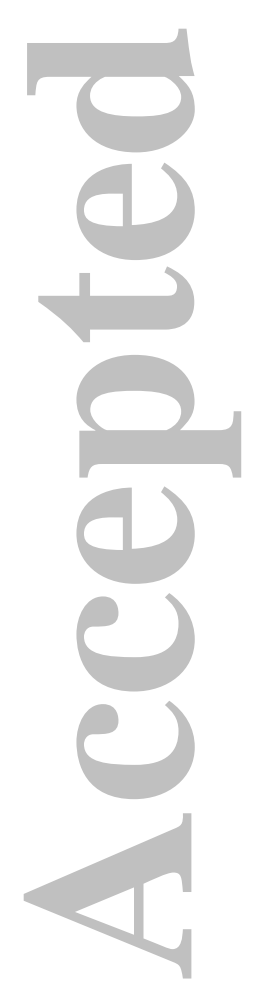


Table 1.

Demographic information for TBI participants and controls seen at 16 years postinjury

\begin{tabular}{cccccc}
\hline Variable & $\begin{array}{c}\text { TBI } \\
(n=28)\end{array}$ & $\begin{array}{c}\text { Control } \\
(n=16)\end{array}$ & $p$ & $t(\mathrm{df}) / \chi^{2}$ & $g / V$ \\
\hline Male, $n(\%)$ & $12(42.90)$ & $11(68.80)$ & .180 & 1.80 & .249 \\
Injury age, $M(S D)$ & $5.04(1.80)$ & - & & & \\
SES, $M(S D)$ & $4.63(0.98)$ & $3.41(1.07)$ & $.001^{*}$ & $3.60(35)$ & 1.20 \\
FSIQ, $M(S D)$ & $100.93(14.38)$ & $111.19(12.12)$ & $.016^{*}$ & $-2.40(42)$ & .754 \\
Age at $16-$ year follow- \\
up, $M(S D)$
\end{tabular}

Note. TBI = Traumatic Brain Injury; FSIQ = Full-Scale Intelligence Quotient; SES = socio-economic status. $t(\mathrm{df})=$ independent samples t-test (degrees of freedom) or chisquare for categorical; $g=$ Hedges' $g$ and Cramer's $V$ for categorical variables. 


\section{Table 2.}

Inferential statistics of executive functioning and volumetric measures between TBI and controls

Variables

Executive Function

Inhibition, $M(S D)$

Cognitive flexibility, $M(S D)$

Inhibition/cognitive flexibility, $M(S D)$

Cortical Matter
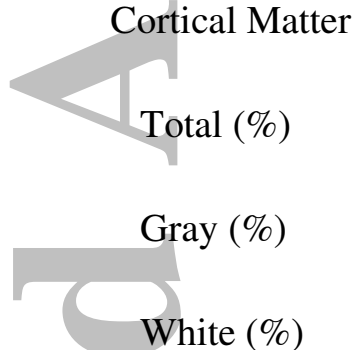

hite $(\%)$
TBI $(n=28) \quad$ Control $(n=16)$

$p$

$t(\mathrm{df})$
10.68 (2.39)

$9.04(2.82)$

$9.75(2.44)$

$10.44(3.05)$

$.417 \quad-0.82(42)$

Note. TBI $=$ Traumatic Brain Injury; $t(\mathrm{df})=t$-test (degrees of freedom).

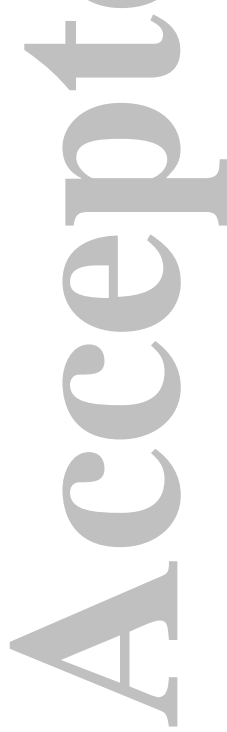


Table 3.

Inferential statistics of executive functioning and volumetric measures across TBI severity subgroups

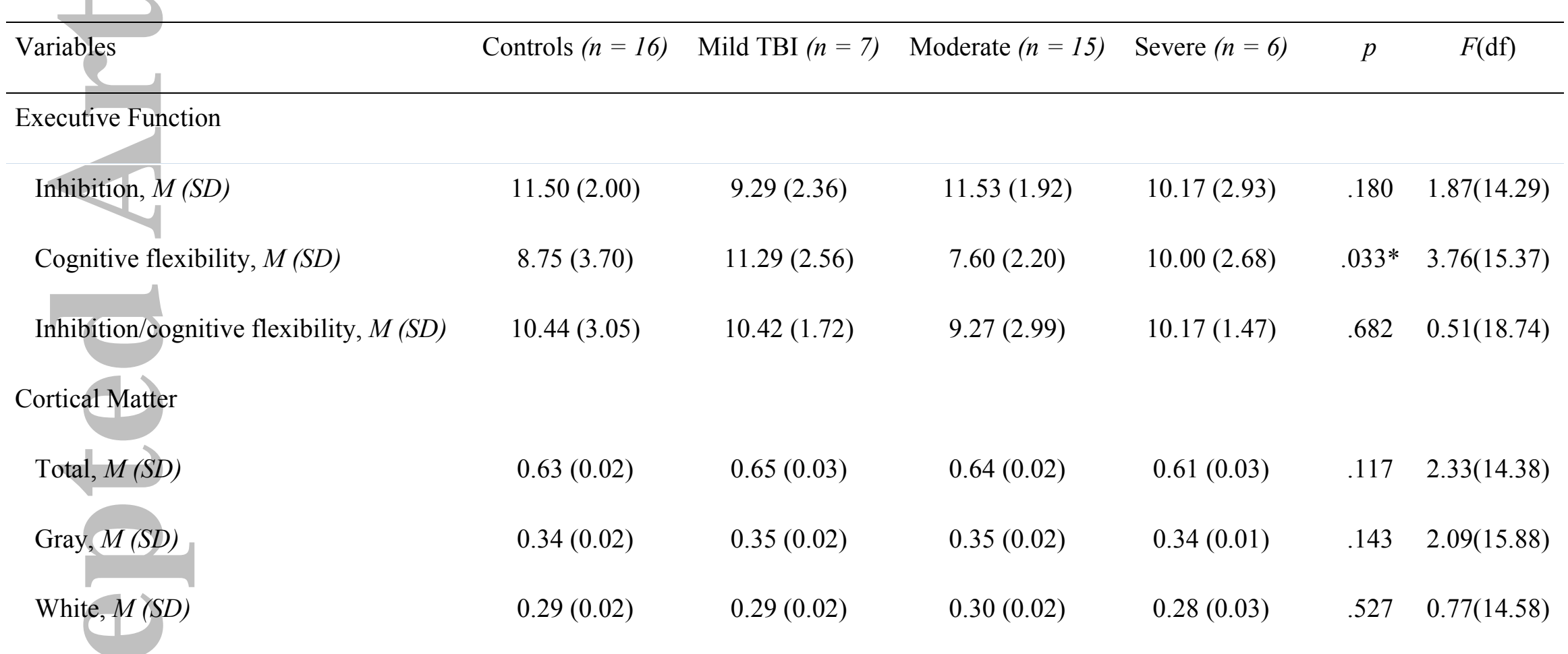

Note $. \mathrm{TBI}=$ Traumatic Brain Injury; $F(\mathrm{df})=$ Welch $F$-statistic (degrees of freedom). 
Table 4.

Summary of hierarchical regression analysis of variables predicting inhibition

\begin{tabular}{|c|c|c|c|c|c|c|}
\hline Variable & B & $t$ & $F\left(\mathrm{df}_{1}, \mathrm{df}_{2}\right)$ & $p$ & $R^{2}$ & $\Delta R^{2}$ \\
\hline Step 1 & & & $0.26(2,41)$ & .771 & .013 & .013 \\
\hline Age & 0.00 & 0.31 & & .975 & & \\
\hline Sex & -0.50 & -0.72 & & .474 & & \\
\hline ep 2 & & & $0.50(3,40)$ & .682 & .036 & .023 \\
\hline ge & .0 .20 & .128 & & .899 & & \\
\hline Sex & -0.33 & -0.46 & & .651 & & \\
\hline Group & 0.75 & 1.00 & & .326 & & \\
\hline $\mathrm{p} 3$ & & & $0.41(4,39)$ & .803 & .040 & .003 \\
\hline Age & 0.01 & .0 .10 & & .921 & & \\
\hline ex & -0.36 & -.0 .49 & & .624 & & \\
\hline Iroup & 0.75 & 0.98 & & .331 & & \\
\hline White matter & 9.35 & -0.38 & & .708 & & \\
\hline $\mathrm{p} 4$ & & & $0.80(5,38)$ & .556 & .095 & .055 \\
\hline Age & -0.00 & -0.02 & & .986 & & \\
\hline Sex & -0.50 & -0.69 & & .497 & & \\
\hline Group & -18.00 & -1.46 & & .152 & & \\
\hline White matter & -89.56 & -1.57 & & .125 & & \\
\hline Group*white matter & 63.89 & 1.53 & & .135 & & \\
\hline
\end{tabular}

Note. Age $=$ Age at 16-year follow-up; $\mathrm{B}=$ Unstandardised Regression Coefficient; $t$ $=t$-test $F\left(\mathrm{df}_{1}, \mathrm{df}_{2}\right)=\mathrm{F}$-statistic (regression $\mathrm{df}$, residual $\left.\mathrm{df}\right) ; \mathrm{R}^{2}=R$-squared; $\Delta R^{2}$ $=$ Change in R-squared. 
Table 5.

Summary of hierarchical regression analysis of variables predicting cognitive flexibility

\begin{tabular}{|c|c|c|c|c|c|c|}
\hline Variable & B & $t$ & $F\left(\mathrm{df}_{1}, \mathrm{df}_{2}\right)$ & $p$ & $R^{2}$ & $\Delta R^{2}$ \\
\hline Step 1 & & & $3.05(2,41)$ & .058 & .130 & .130 \\
\hline ge & -0.02 & -0.12 & & .907 & & \\
\hline & 2.23 & 2.47 & & .018 & & \\
\hline 2 & & & $2.02(3,40)$ & .127 & .132 & .002 \\
\hline & -0.02 & -0.09 & & .932 & & \\
\hline & 2.30 & 2.44 & & $.019 *$ & & \\
\hline Group & 0.30 & 0.31 & & .760 & & \\
\hline & & & $1.67(4,39)$ & .177 & .146 & .014 \\
\hline & -0.01 & -0.03 & & .977 & & \\
\hline & 2.40 & 2.51 & & $.016^{*}$ & & \\
\hline Group & 0.30 & 0.31 & & .761 & & \\
\hline White matter & 20.18 & -0.81 & & .422 & & \\
\hline tep 4 & & & $1.57(5,38)$ & .191 & .171 & .025 \\
\hline Age & -0.02 & -0.12 & & .911 & & \\
\hline Sex & 2.27 & 2.37 & & $.023 *$ & & \\
\hline Group & -17.20 & -1.06 & & .297 & & \\
\hline White matter & -56.70 & -0.75 & & .457 & & \\
\hline Group*white matter & 59.94 & 1.08 & & .288 & & \\
\hline
\end{tabular}

1

Journal of Neuroscience Research

This article is protected by copyright. All rights reserved. 
Note. Age $=$ Age at 16 -year follow-up; $\mathrm{B}=$ Unstandardised Regression Coefficient; $t$ $=t$-test; $F\left(\mathrm{df}_{1}, \mathrm{df}_{2}\right)=\mathrm{F}$-statistic (regression $\mathrm{df}$, residual $\mathrm{df}$ ); $\mathrm{R}^{2}=R$-squared; $\Delta R^{2}$ $=$ Change in R-squared.
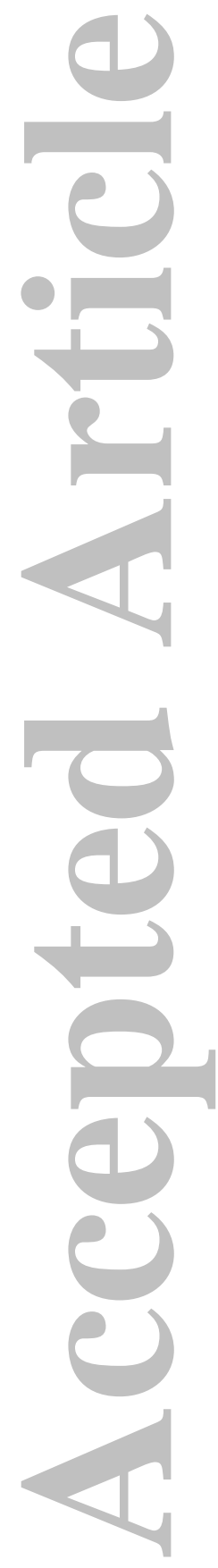
Table 6.

Summary of hierarchical regression analysis of variables predicting inhibition/cognitive flexibility

\begin{tabular}{|c|c|c|c|c|c|c|}
\hline Variable & $\mathrm{B}$ & $t$ & $F\left(\mathrm{df}_{1}, \mathrm{df}_{2}\right)$ & $p$ & $R^{2}$ & $\Delta R^{2}$ \\
\hline Step 1 & & & $1.94(2,41)$ & .157 & .086 & .086 \\
\hline Age & -0.02 & -0.13 & & .895 & & \\
\hline Sex & 1.55 & 1.97 & & .056 & & \\
\hline Step 2 & & & $1.96(3,40)$ & .136 & .128 & .042 \\
\hline ge & 0.00 & 0.00 & & 1.00 & & \\
\hline & 1.83 & 2.27 & & $.029 *$ & & \\
\hline Group & 1.16 & 1.38 & & .175 & & \\
\hline & & & $1.49(4,39)$ & .225 & .132 & .004 \\
\hline & 0.01 & 0.03 & & .975 & & \\
\hline & 1.87 & 2.28 & & $.028^{*}$ & & \\
\hline Group & 1.16 & 1.37 & & .179 & & \\
\hline hite matter & 9.35 & 0.44 & & .664 & & \\
\hline p 4 & & & $2.48(5,38)$ & $.049 *$ & .246 & $.114^{*}$ \\
\hline Age & -0.02 & -0.16 & & .878 & & \\
\hline Sex & 1.64 & 2.10 & & $.042 *$ & & \\
\hline Group & -30.44 & -2.30 & & $.027 *$ & & \\
\hline White matter & -129.50 & -2.11 & & $.042 *$ & & \\
\hline Group*white matter & 107.70 & 2.40 & & $.022 *$ & & \\
\hline
\end{tabular}

Journal of Neuroscience Research

This article is protected by copyright. All rights reserved. 
Note. Age $=$ Age at 16-year follow-up; $\mathrm{B}=$ Unstandardised Regression Coefficient; $t$ $=t$-test; $F\left(\mathrm{df}_{1}, \mathrm{df}_{2}\right)=\mathrm{F}$-statistic (regression $\mathrm{df}$, residual $\mathrm{df}$ ); $\mathrm{R}^{2}=R$-squared; $\Delta R^{2}$ $=$ Change in R-squared.
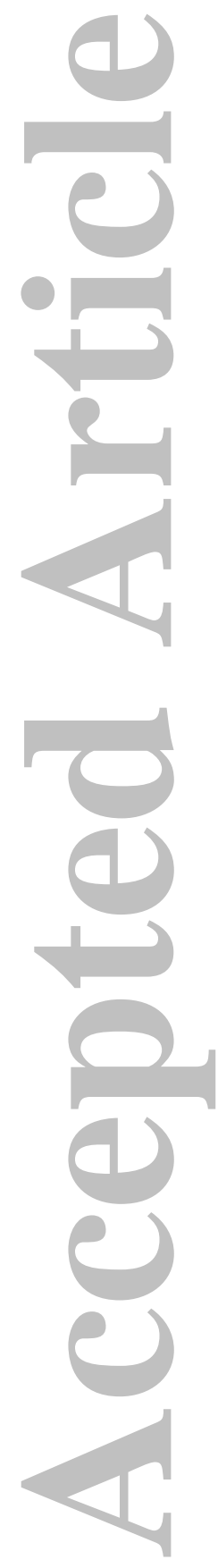


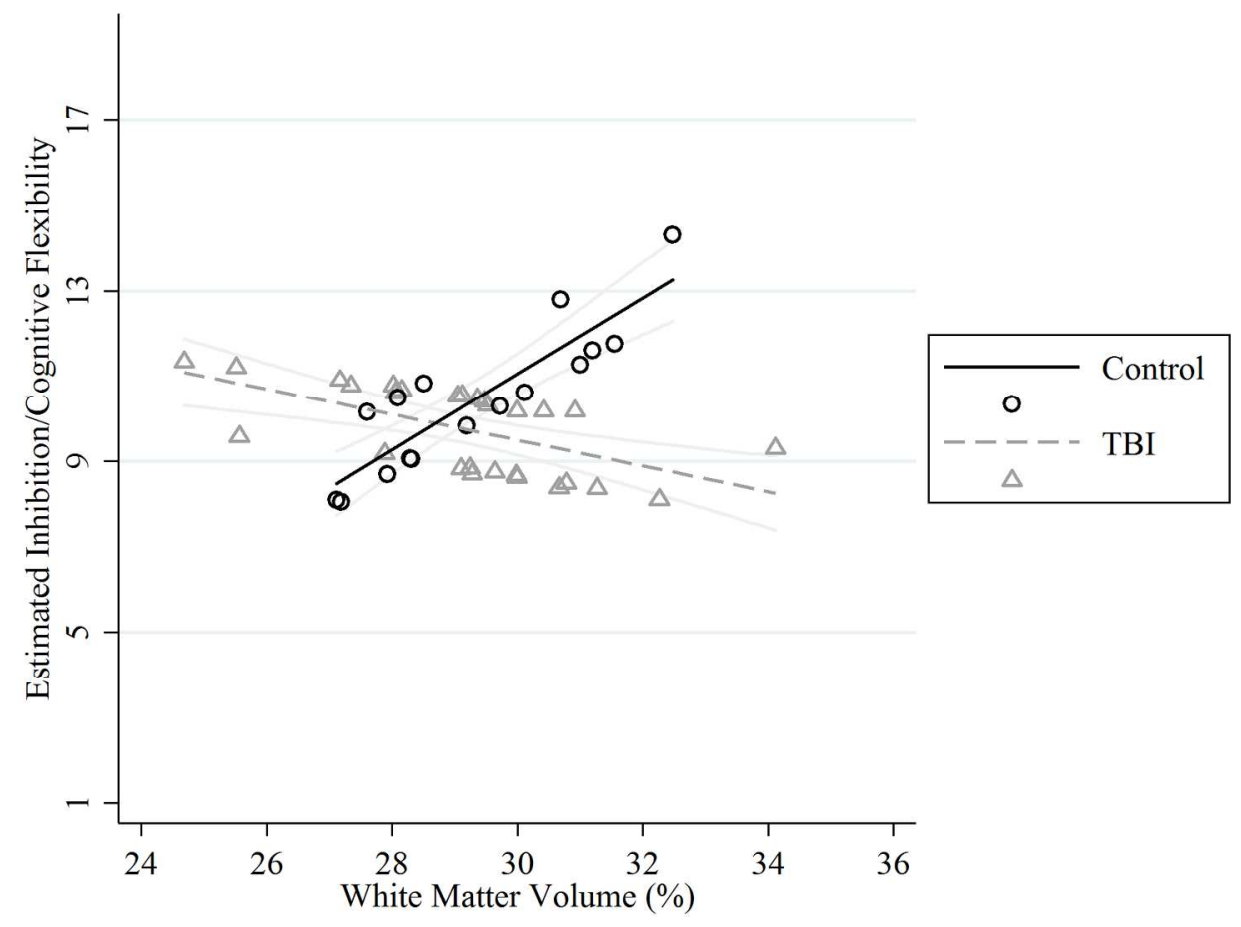

Brain-behavior relationship underlying inhibition/cognitive flexibility performance between typically developing controls and childhood Traumatic Brain Injury (TBI) group and white matter volume.

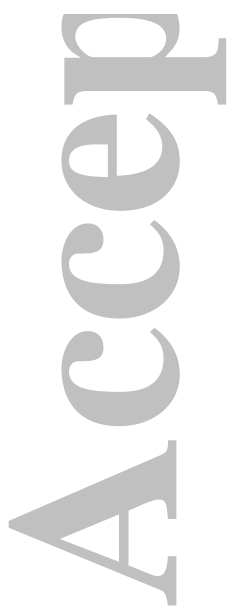

$169 \times 127 \mathrm{~mm}(300 \times 300$ DPI $)$ 
Figure Legends for Supplementary Material

Figure 1. Boxplot depicting distribution of executive function measures.
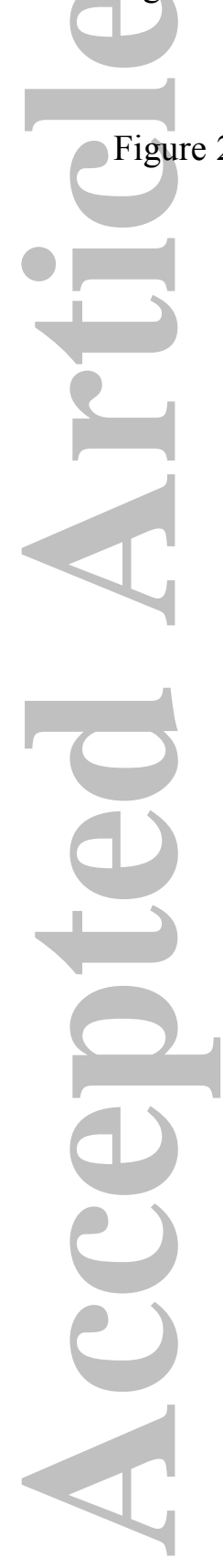

Journal of Neuroscience Research

This article is protected by copyright. All rights reserved. 

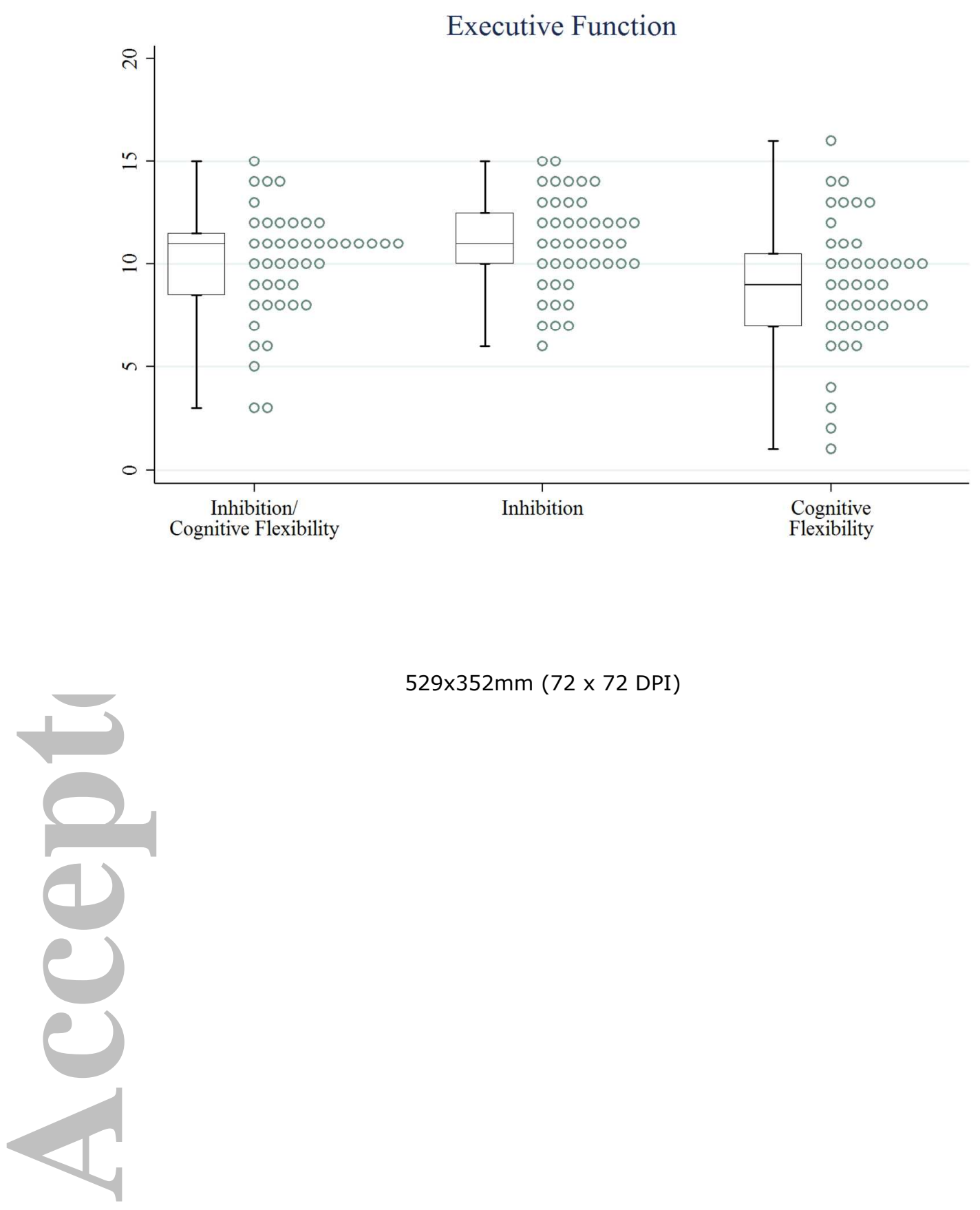

$529 \times 352 \mathrm{~mm}(72 \times 72 \mathrm{DPI})$

Journal of Neuroscience Research

This article is protected by copyright. All rights reserved. 


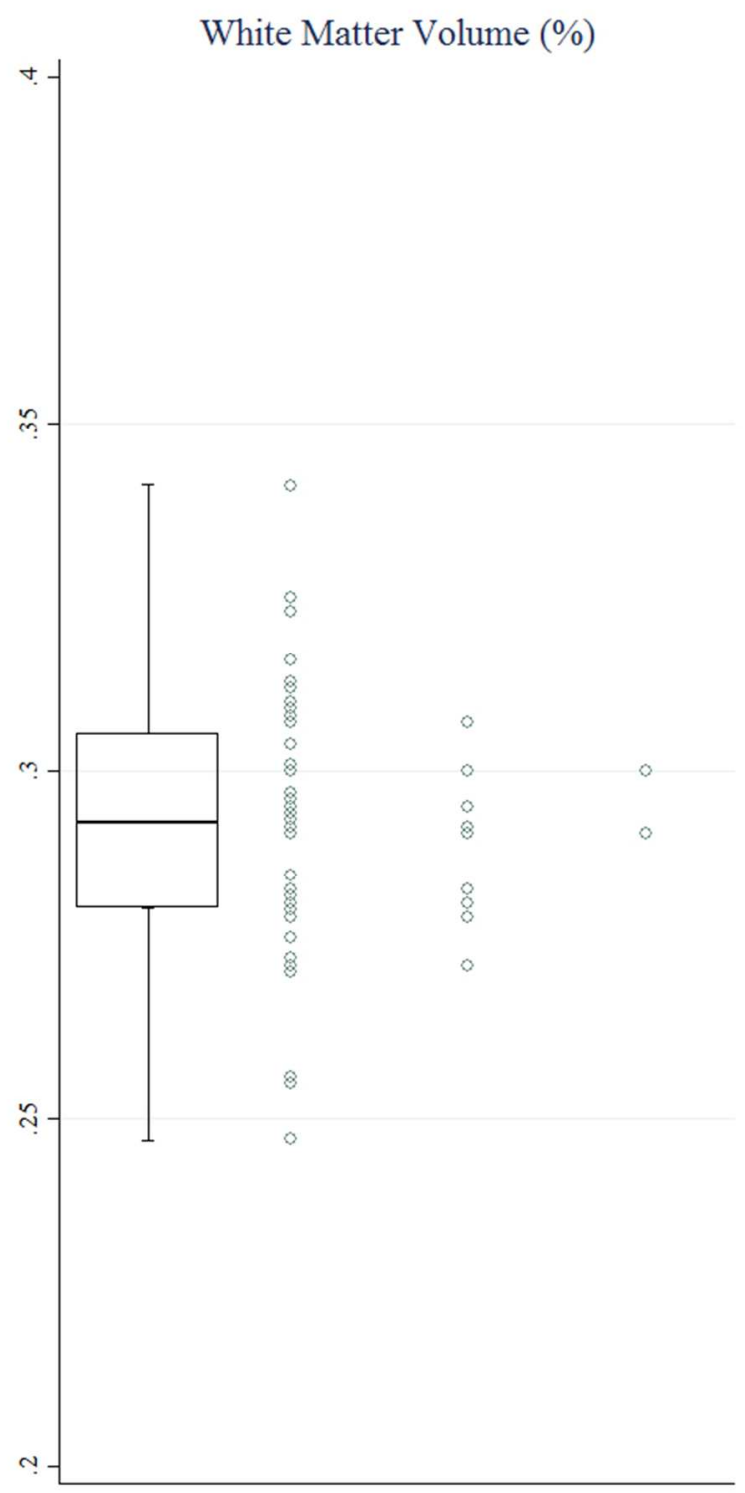

$176 \times 352 \mathrm{~mm}(72 \times 72$ DPI $)$

Journal of Neuroscience Research

This article is protected by copyright. All rights reserved. 


\section{Graphical Abstract}

16 years following childhood Traumatic Brain Injury (TBI), survivors did not differ from age-matched controls on executive function measures and white matter volume. However, childhood TBI survivors did not reflect the typical brain behavior relationship that characterized executive function in adulthood, $r$ sugge

suggesting disruptions in the whole brain underpinning executive function.
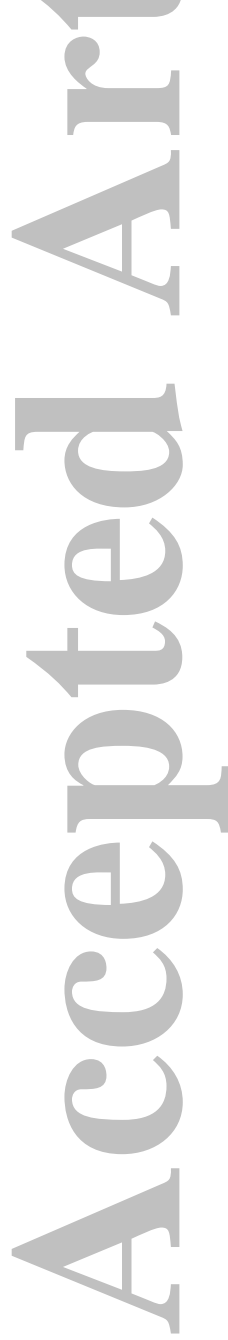

Journal of Neuroscience Research

This article is protected by copyright. All rights reserved. 


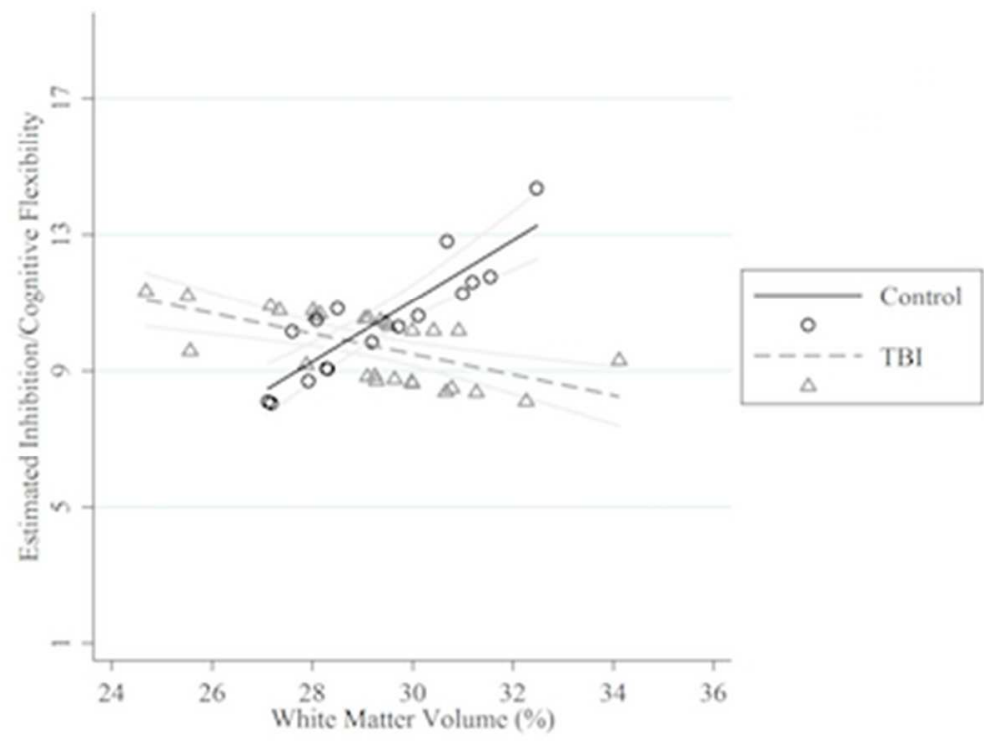

Brain-behavior relationship underlying inhibition/cognitive flexibility performance between typically developing controls and childhood Traumatic Brain Injury (TBI) group and white matter volume.

$141 \times 105 \mathrm{~mm}(72 \times 72 \mathrm{DPI})$

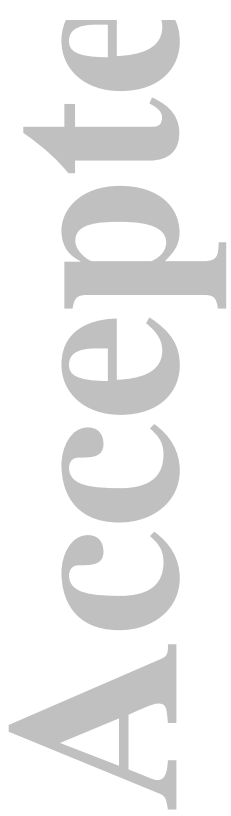

Journal of Neuroscience Research

This article is protected by copyright. All rights reserved. 


\section{University Library}

\section{- M M N E R VA A gateway to Melbourne's research publications}

Minerva Access is the Institutional Repository of The University of Melbourne

Author/s:

Yu, K;Seal, ML;Reyes, J;Godfrey, C;Anderson, V;Adamson, C;Ryan, NP;Hearps,

SJC;Catroppa, C

Title:

Brain volumetric correlates of inhibition and cognitive flexibility 16 years following childhood traumatic brain injury

Date:

2018-04-01

Citation:

Yu, K., Seal, M. L., Reyes, J., Godfrey, C., Anderson, V., Adamson, C., Ryan, N. P., Hearps, S. J. C. \& Catroppa, C. (2018). Brain volumetric correlates of inhibition and cognitive flexibility 16 years following childhood traumatic brain injury. JOURNAL OF NEUROSCIENCE RESEARCH, 96 (4), pp.642-651. https://doi.org/10.1002/jnr.24087.

Persistent Link:

http://hdl.handle.net/11343/293146 